\title{
Anaphylactic Shock Due to Psyllium (Plantago ovata Seed) Allergy: A Case Report
}

\section{Paula Ollo Morales, Marta Velasco Azagra, Carlota Martel Martin, Marta Gutiérrez Niso, Nagore Bernedo Belar, Maria Teresa Audicana Berasategui}

\begin{abstract}
Allergy and Immunology Department, Hospital Universitario Araba (HUA), Vitoria-Gasteiz, Spain
\end{abstract}
Email: paula.ollomorales@osakidetza.eus

How to cite this paper: Morales, P.O., Azagra, M.V., Martin, C.M., Niso, M.G., Belar, N.B. and Berasategui, M.T.A. (2022) Anaphylactic Shock Due to Psyllium (Plantago ovata Seed) Allergy: A Case Report. Food and Nutrition Sciences, 13, 1-5. https://doi.org/10.4236/fns.2022.131001

Received: December 3, 2021

Accepted: January 8, 2022

Published: January 11, 2022

Copyright ( 2022 by author(s) and Scientific Research Publishing Inc. This work is licensed under the Creative Commons Attribution International License (CC BY 4.0).

http://creativecommons.org/licenses/by/4.0/

\begin{abstract}
The seeds of Plantago ovata, called psyllium or ispaghula, have been used in the preparation of bulk laxatives. Nowadays, it is also used as an ingredient in bakery and breakfast cereals to increase dietary fiber and to give baking products fluffiness and viscosity. Mostly, there are described cases of occupational allergy that handle Plantago ovata seeds in powder laxatives and some cases of anaphylaxis after eating products containing psyllium. This case report is about a geriatric assistant who had an anaphylactic shock after eating a multigrain gluten-free piece of bread containing psyllium, who presented a positive skin test with psyllium in the allergy study. We recommended to the patient to avoid the ingestion and the inhalation at work of Plantago ovata seeds and to carry self-injectable adrenaline. With this case, we would like to highlight the growing uses of psyllium, especially in bakery products, and that it can behave like a hidden allergen.
\end{abstract}

\section{Keywords}

Plantago ovata, Psyllium, Ispaghula, Anaphylaxis, Occupational Allergy

\section{Introduction}

Plantago ovata is a plant of the Plantaginaceae family, native from Asia, the Mediterranean region and North Africa. The seeds of Plantago ovata ( $P$. ovata) are called psyllium or ispaghula and are small brown seeds that look like fleas, hence their Greek name psyllium [1]. These seeds have been used since ancient times in the preparation of bulk laxatives. The laxative properties of $P$. ovata seeds are based on the hydrophilic properties of its cuticle, from which soluble fiber is obtained. This fiber, once in the digestive system, retains water increasing the volume of fecal mass and therefore, peristalsis is stimulated, facilitating intestinal 
transit. Nowadays, laxatives containing $P$. ovata seeds are traded in powdered or granulated formulations such as Cenat ${ }^{\varpi}$ or Plantaben ${ }^{\circledast}$ in Spain. In North America and Australia, the seeds of $P$. ovata have also been used as an ingredient in breakfast cereals to reduce serum cholesterol levels and to increase dietary fiber [2].

Asher described the first case of allergy to psyllium in 1941 [3]. Since then, several cases of allergy have been described. It has been defended that patients with allergies to these seeds are sensitized by inhalation after handling $P$. ovata seed powder during the preparation of laxatives [4]. In the scientific literature, a case of death secondary to a severe asthma attack is described after manipulation of a laxative with $P$. ovata seeds in a nurse, being diagnosed post mortem of anaphylaxis by inhalation of psyllium [5]. Despite this, most of the cases described work around people who have suffered anaphylaxis after consuming $P$. ovata seeds in breakfast cereals or in laxatives [6] [7] [8] [9] [10], including a case of anaphylactic death [11]. Recently, a case of rhino-conjunctivitis due to allergy to psyllium has been described in a 24-year-old female baker after manipulating gluten-free flour-mix for a year [12].

The following risk groups have been described for the development of allergy to psyllium [13]: workers in the pharmaceutical industry who handle laxatives with $P$. ovata seeds powder, health care professionals who prepare this type of laxatives for consumption by patients and to a lesser extent in the consumers of the product themselves. The prevalence of allergy to $P$. ovata seeds or psyllium in health care professionals in a cross-sectional epidemiologic study made in our area (Regional Social Welfare Institute) resulted in 8.6\% [14]. Patients (nurses and nursing assistants) recruited for this study presented mainly rhino-conjunctivitis and asthma after the manipulation of $P$. ovata seeds in powdered laxatives [14].

\section{Case Report}

We present a 35-year-old woman without morbidity except a mild rhino-conjunctivitis due to pollen allergy, geriatric assistant working in a nursing home, who was referred to the allergy department from the emergency room on the suspicion of an anaphylactic shock due to Cefuroxime (beta-lactam antibiotic). The patient was taking Cefuroxime to treat a respiratory infection. During the interview in the allergy department, the patient stated that the episode occurred after taking not only the antibiotic but also the multi-seed gluten-free bread. Five to ten minutes after eating the multi-seed gluten free piece of bread (around 20 grams) without other accompanying foods, she presented generalized itching, suffocation, chest pain and dizziness. In the emergency room, the clinicians observed an urticarial rash, eyelid angioedema, arterial hypotension and tachycardia. The patient recovered in two hours approximately after receiving adrenaline and other drugs. In a posterior interview with the patient, a prior incident was revealed which featured oral pruritus and stomach ache when consuming the same product. 
The allergy study consisted of skin tests with plant pan-allergens, the involved product and its components (sesame seeds, chia, almond, yeast and psyllium and its flour). We did not perform skin tests with ingredients like starch or other components due to their limited involvement in allergic reactions. In addition, a blood test was performed with total IgE and specific IgE for ispaghula, plant pan-allergens and wheat (by usual protocol of food allergy study). Furthermore, a standard study of beta-lactam antibiotic allergy was carried out (skin test and drug controlled provocation test) and a controlled provocation test with other ingredients of the bread except for psyllium, on different days in two hours each.

The results showed a positive skin test with the implicated bread and negative with the plant pan-allergens, wheat and beta-lactam antibiotics. Further, we observed a positive skin test with psyllium (Figure 1) and a negative test with the rest of the ingredients of the bread (sesame seeds, chia, almond and yeast). The blood analysis showed a total IgE of $190 \mathrm{kUA} / \mathrm{L}$ (normal range up to $100 \mathrm{kUA} / \mathrm{L}$ ), a negative specific IgE for seed and plant pan-allergens and a positive specific IgE for ispaghula $(0.50 \mathrm{kUA} / \mathrm{L})$. Taking into account all the results of complementary tests, a controlled exposure was carried out with Cefuroxime (implicated drug) and with the rest of the ingredients of the bread except psyllium. The patient tolerated yeast, chia, almond, sesame seeds and Cefuroxime without showing a reaction.

We recommended the patient to avoid the ingestion of psyllium and the manipulation of $P$. ovata seeds in powdered laxatives at work. In addition, we recommended carrying self-injectable adrenaline always.

\section{Discussion}

We describe a case of anaphylactic shock due to the ingestion of psyllium or $P$. ovata seeds in the gluten-free bread. In this patient, psyllium behaved as a hidden

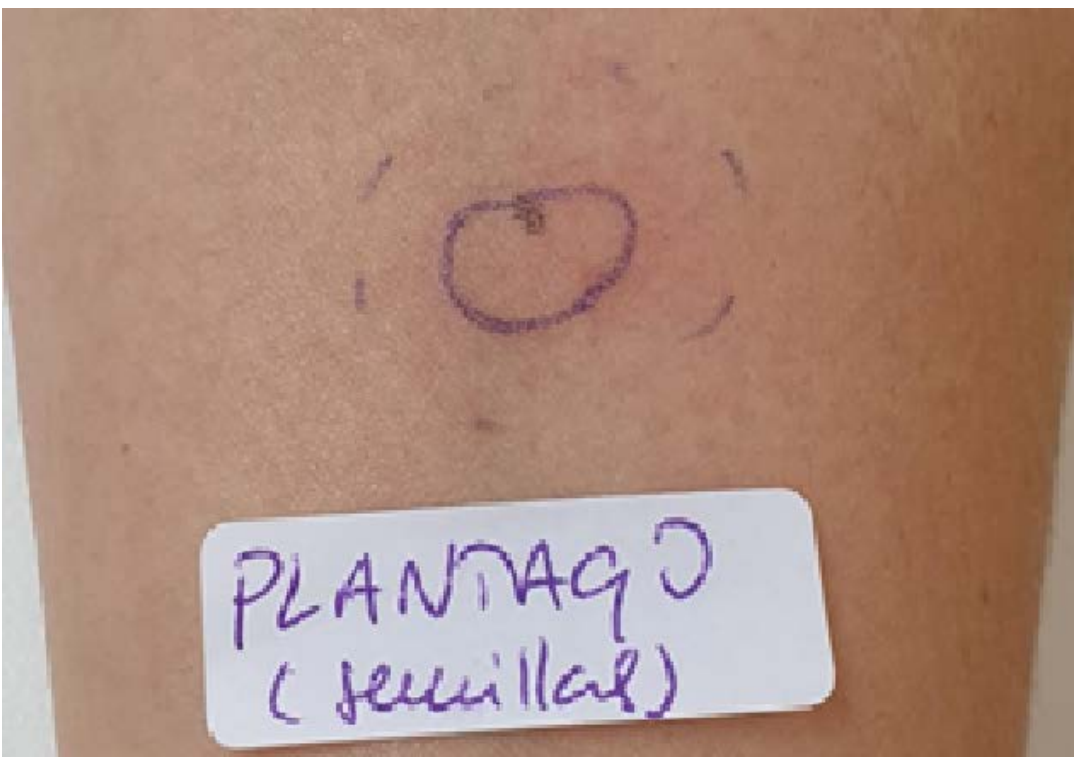

Figure 1. Result of skin prick tests with Plantago ovata seed. 
allergen as the initial suspicion was drug anaphylaxis. Given our previous experience in allergy to $P$. ovata seeds among health workers, we suggest that our patient was sensitized by inhalation in the workplace, although we mustn't discard the possibility of an oral sensitization after eating the multi-seed bread.

We would like to highlight the new and growing uses of $P$. ovata seeds or psyllium, especially in gluten-free products becoming a common ingredient in baking because of its binding effect, used as a substitute for gluten. As explained in the introduction, psyllium absorbs water and creates mucilages, increasing the volume of the dough and giving the baking products fluffiness and viscosity. Taking into account the wide distribution and growing consumption of these products, it should be considered an allergen [15]. Some authors describe that hidden allergens account for almost a quarter (21\%) of all food allergy reactions [16]. Nowadays, $P$. ovata seeds or psyllium are not considered a declared food allergen, like sesame seeds, nuts, egg, soybean or others despite the hidden risks shown in this study [17].

This case confirms that $P$. ovata seeds or psyllium should be considered as a potential life threatening allergen. The number of population that consumes gluten free products is gradually increasing including celiac, intolerant, low FODMAP diet and allergic patients. What is more, $P$. ovata seeds are not considered as a drug but as a natural product, therefore it does not require a medical prescription. This increases the risk of allergic reactions in regular consumers and especially amongst health workers.

\section{Conclusion}

In conclusion, all professionals involved in jobs related to health and food should be informed about this topic, as $P$. ovata seeds or psyllium are an emerging hidden allergen.

\section{Consent}

The patient gave written informed consent for publication of this case report.

\section{Conflicts of Interest}

All the authors declare that they do not have conflicts of interest. No funding was provided for this research.

\section{References}

[1] Aleman, A.M., Quirce, S., Bombin, C. and Sastre, J. (2001) Asthma Related to Inhalation of Plantago ovata. Medicina Clínica (Barc), 116, 20-22. https://doi.org/10.1016/S0025-7753(01)71705-8

[2] James, J.M., Cooke, S.K., Barnett, A. and Sampson, H.A. (1991) Anaphylactic Reactions to a Psyllium-Containing Cereal. Journal of Allergy and Clinical Immunology, 88, 402-408. https://doi.org/10.1016/0091-6749(91)90104-V

[3] Ascher, M.S. (1941) Psyllium Seed Sensitivity. Journal of Allergy, 12, 607-609. https://doi.org/10.1016/S0021-8707(41)90211-3 
[4] Schoenwetter, W.F. and Steinberg, P. (1985) Psyllium Hypersensitivity, Nurses, and Geriatric Units. Annals of Internal Medicine, 103, 642. https://doi.org/10.7326/0003-4819-103-4-642

[5] Hoffman, D. (2006) Psyllium: Keeping This Boon for Patients from Becoming a Bane for Providers. Journal of Family Practice, 55, 770-772.

[6] Drake, C.L., Moses, E.S. and Tandberg, D. (1991) Systemic Anaphylaxis after Ingestion of a Psyllium-Containing Breakfast Cereal. The American Journal of Emergency Medicine, 9, 449-451. https://doi.org/10.1016/0735-6757(91)90212-3

[7] Lantner, R.R., Espiritu, B.R., Zumerchik, P. and Tobin, M.C. (1990) Anaphylaxis Following Ingestion of a Psyllium-Containing Cereal. Journal of the American Medical Association, 264, 2534-2536. https://doi.org/10.1001/jama.1990.03450190066030

[8] German, A., Aregall, S., Boada, L. and Tomas, S. (1995) Anaphylactic Shock Following the Ingestion of a Laxative. Medicina Clínica (Barc), 104, 559.

[9] Vaswani, S.K., Hamilton, R.G., Valentine, M.D. and Adkinson, N.F. (1996) Psyllium Laxative-Induced Anaphylaxis, Asthma, and Rhinitis. Allergy, 51, 266-268.

https://doi.org/10.1111/j.1398-9995.1996.tb04604.x

[10] Zaloga, G.P., Hierlwimmer, U.R. and Engler, R.J. (1984) Anaphylaxis Following Psyllium Ingestion. Journal of Allergy and Clinical Immunology, 74, 79-80. https://doi.org/10.1016/0091-6749(84)90091-5

[11] Khalili, B., Bardana, E.J. and Yunginger, J.W. (2003) Psyllium-Associated Anaphylaxis and Death: A Case Report and Review of the Literature. Annals of Allergy, Asthma \& Immunology, 91, 579-584. https://doi.org/10.1016/S1081-1206(10)61538-4

[12] Jungewelter, S., Suomela, S. and Airaksinen, L. (2021) Occupational IgE-Mediated Psyllium Allergy in Contemporary Gluten-Free and Vegan Baking: A Case of Allergic Rhinitis. American Journal of Industrial Medicine, 64, 431-434. https://doi.org/10.1002/ajim.23238

[13] Hinojosa, M., Dávila, I., Zapata, C., Cuesta, J. and Quirce, S. (1990) Asma ocupacional inducido por semillas de Plantago ovata en trabajadores de la industria farmaceútica. Revista Española de Alergología e inmunología Clínica, 5, 139-145.

[14] Bernedo, N., García, M., Gastaminza, G., Fernández, E., Bartolomé, B., Algorta, J., et al. (2008) Allergy to Laxative Compound (Plantago ovata Seed) among Health Care Professionals. The Journal of Investigational Allergology and Clinical Immunology, 18, 181-189.

[15] Skypala, I.J. (2019) Food-Induced Anaphylaxis: Role of Hidden Allergens and Cofactors. Frontiers in Immunology, 10, Article No. 673. https://doi.org/10.3389/fimmu.2019.00673

[16] Añíbarro, B., Seoane, F.J. and Múgica, M.V. (2017) Involvement of Hidden Allergens in Food Allergic Reactions. The Journal of Investigational Allergology and Clinical Immunology, 17, 168-172.

[17] Naska, A., Aggett, P., Bou, M.C., Cubadda, F., McArdle, H.J. and Vinceti, M. (2021) Scientific Panel on Nutrition, Novel Foods and Food Allergens. https://www.efsa.europa.eu/sites/default/files/wgs/nutrition/wg-upper-levels.pdf 